\title{
Becoming a teacher in higher education: Creating an academic development program to catalyse doctoral students' professionalization
}

\author{
GORANA MISIC $^{1 *}$ (D), MARGARYTA RYMARENKO ${ }^{2}$ (1) and \\ HELGA DORNER ${ }^{3}$
}

\author{
${ }^{1}$ Bard College Berlin, Germany \\ ${ }^{2}$ Central European University, Vienna, Austria \\ ${ }^{3}$ Eötvös Loránd University, Budapest, Hungary
}

\section{THEMATIC ARTICLE}

Received: November 26, 2020 • Accepted: May 17, 2021

Published online: July 30, 2021

(C) 2021 The Author(s)

\begin{abstract}
This paper focuses on exploring the intellectual basis for establishing an academic development program for international doctoral students in social sciences and humanities in Central Europe so as to cultivate a reflective scholarly approach to teaching early on in their academic career. The program conceptions and practices are embedded in the notion that a scholarly approach to teaching integrates the understanding and demonstration of knowledge about teaching and necessitates a continuous learning process about teaching through reflection and through conducting research on teaching in the various disciplines. In particular, taking on board the domains of teaching knowledge which derived from the kinds of reflections on teaching (cf. Kreber \& Cranton, 2000; Mezirow, 1991), instructional, pedagogical and curricular knowledge and continuous reflection at the level of content, process as well as premise, are represented in an integrative manner in our overarching program principles and pedagogical strategies. As we see, professionalization of doctoral students' teaching practice in higher education (cf. Lueddeke, 2003) is particularly important in the context of enhanced faculty mobility and internationalization. Therefore, this paper aims to contribute to the literature and practice on establishing academic development programs, especially in academic environments with low institutional support for teaching and lack of formal requirements for professional development.
\end{abstract}

\footnotetext{
* Corresponding author. E-mail: g.misic@berlin.bard.edu
} 


\section{KEYWORDS}

academic development, novice teachers, professionalization program, reflection

\section{INTRODUCTION}

A growing demand for excellence in teaching has increased in the past decades and thus encouraged universities to think more strategically about the professional development of their faculty. This resulted in a proliferation of Centers for Teaching and Learning (CTLs) in supporting academic development and teaching excellence (Jacob, Xiong, \& Ye, 2015; Jerez Yàñez, Aranda Càceres, Corvalán Canessa, González Rojas, \& Ramos Torres, 2019). CTLs have diverse organizational structures and principles shaped by the unique institutional contexts in which they exist. Within these institutional cultures CTLs act as 'facilitators or catalysts of change' (Jacob et al., 2015; Kelley, Cruz, \& Fire, 2017). Among multiple engagements, their primary mandate is to induct novice and new faculty in the teaching culture of the institution and to support faculty in their advancement as teachers through various academic development programs. Such programs and academic activities have been praised for their contribution to developing a repertoire of teaching skills (Feixas \& Euler, 2012), changing approaches to and conceptions of teaching and learning (Ho, Watkins, \& Kelly, 2001), and adopting the perspective of the student learning approach (Gibbs \& Coffey, 2004; Nyquist \& Sprague, 1998). Moreover, academic development programs are particularly important in the context of enhanced faculty mobility and internationalization, which propelled the ever-increasing need for professionalization in the field (cf.Lueddeke, 2003; Pylväs \& Nokelainen, 2021). However, due to research performance pressure and historic traditions that have implications for academics' conceptions of and attitudes towards teaching, faculty may feel reluctant to invest in academic development. Although there is no simple narrative of a "teaching and research divide" (Clegg, 2009, p. 407), faculty are socialized into at least two roles: researcher and teacher. These roles may often be perceived as being far from complementary activities. In fact, Ramsden (1994) claims that these activities are either unrelated or negatively correlated. Further, Hattie and March (1996) assert that these roles are associated with different expectations and obligations underpinned by differing reward systems, hence the possible tension between them. Structural changes thus have generated a culture of audit and managerialism that surfaced demands for accountability, performance, and productivity in both areas of responsibility (Ball, 2003; Clegg, 2009). Academic development may thus be seen as yet another activity that is elicited through the sanctions and rewards of performance (often contrasting with research performance) and therefore not so much driven by professional growth (cf. Deaker, Stein, \& Spiller, 2016; Quinn, 2012).

In this context, as Deaker et al. (2016, p. 309) suggest, there is a need to "consider the following: exploring identity beyond the discipline; deeper questioning of beliefs about teaching that underlie the practices and skills; aligning student-teacher value and power relationships; exploring how performativity and quality control work alongside each other; and aligning performance with professional development." These were some of the main considerations also when founding the Center for Teaching and Learning at the Central European University (CEU CTL), which comprised teaching and learning scholars who work with doctoral students and faculty across all departments and schools within the University. Aiming to first cultivate the overarching notion of teaching excellence and reflexivity in academic practice, and being mindful of 
the lack of formal requirements for professional development for faculty, the CEU CTL developed an academic development program for doctoral students whose first encounters with university teaching took place during their teaching assistantships facilitated by their professors at their departments. The program is anchored in key pedagogical principles, which are as follows: (1) peer teaching as a strategy to close the gap between the theory and practice of teaching, (2) design for student learning to develop instructional knowledge about course design, instructional and assessment strategies, and, finally, (3) supporting the process of becoming, that is, developing an awareness about research behind teaching and of critical skills for reflection which needs sustained and ongoing scaffolding during a longer period of time. These principles are of equal relevance and weight in the program and thus are manifested in pedagogical strategies, such as collaborative session- and syllabus designs and co- or peer-teaching, as well as scaffolded writing assignments (e.g. letters to future selves, teaching philosophy statement, observation notes and annotated session plans, etc.) which focus on developing skills of reflection on professional practice.

The aim of this paper is thus to provide a synthesis of 'big ideas' or principles that underpin this particular academic development program for doctoral students. It is thus neither a purely theoretical nor an empirical endeavour but, we hope, a meaningful description of a framework for program theory (cf. Rogers, Petrosino, Huebner, \& Hacsi, 2000), which may inform the formative analysis of pedagogical practices - within this program or beyond - without the pressure of causal attributions.

\section{The institutional context}

CEU is a highly international university with US, Hungarian and Austrian accreditation in social sciences and humanities. Compared to other institutions, CEU's doctoral students also have very limited opportunities to practice their teaching skills, as the University's main teaching profile until recently has been graduate education. Moreover, CEU doctoral graduates most likely continue their academic careers in the international job market, which implies higher faculty mobility; and requires skills of adaptation and professionalization of their disciplinary as well as globally-relevant generic teaching practices.

Therefore, the CTL Certificate Program for Excellence in Teaching in Higher Education (CTL Certificate Program) for doctoral students is crucial for cultivating a reflective scholarly approach to teaching early on in their academic career - even if more robust teaching experience will be gained at a later career stage. The program conceptions and practices are thus embedded in the notion that a scholarly approach to teaching integrates the understanding and demonstration of knowledge about teaching. It necessitates a continuous learning process about teaching through reflection and through conducting research on teaching in the various disciplines. In particular, the program takes on board instructional, pedagogical, and curricular knowledge (cf. Kreber \& Cranton) as well as continuous reflection at the level of content, process, and premise (cf. 2000; Mezirow, 1991). These elements are represented in an integrative manner in our overarching program principles and pedagogical strategies.

\section{The CTL Certificate Program in a nutshell}

The CTL Certificate Program consists of a semester-long foundational course in teaching in higher education, two additional advanced inquiry-based seminars; and a capstone course on the development of an online teaching portfolio. 
The core part of the program is the course on Foundations in Teaching in Higher Education (3 ECTS), where students have the opportunity to enact what they are learning in the course through a peer-teaching exercise. By inquiring into the intellectual work of teaching in higher education, the main aim of the course is to facilitate students' preparation for their future academic careers and develop participants' critical self-awareness regarding the complex requirements of good university teaching. The course more generally provides a collaborative, supportive environment, and the community of academic practice.

Students are further offered a choice of advanced inquiry-based seminars (1 ECTS each), which expose them to fundamental issues of teaching and learning in higher education, and require the production of sample teaching designs. These focused seminars cover a variety of topics, including design for learning, diversity, experiential learning, teaching critical thinking, or using podcasts in teaching. In the capstone stage of the program, students take the Starting Your Teaching Portfolio seminar and produce an online teaching portfolio as the basis for ongoing professional development in teaching.

The program design, content, and core values are informed by relevant research on professional development: peer-teaching, design for learning and facilitation of 'becoming' a selfreflective scholar-teacher. The peer-teaching element facilitates design thinking, reflection on enactment in teaching, as well as modelling of certain instructional behaviours. In doing so, peer teaching addresses the issue of meagre teaching opportunities in the institutional context. Further to that, through the advanced seminars the Program also facilitates the 'general' shift from teaching and self to students (student-centeredness) which is further explored in the disciplinary contexts by focusing on disciplinary design thinking and situated student learning. Finally, the program aims to develop an awareness about research behind teaching and of critical skills for reflection and self-analysis, which is reflected in a final program artifact, the online teaching portfolio. In the following, we discuss pedagogical strategies that are grounded in these principles.

\section{Core principles}

The core principles behind the program are anchored in the institutional context which is characterized as a highly international environment with meagre teaching opportunities for doctoral students. Building on this professional need of the target audience to practice teaching, the Program provides the 'peer teaching' experience as an integrated pedagogical strategy (Deshler, Dorner, \& Renc-Roe, 2016). It integrates the scholarship on enactment of practice as well as co-construction of teaching material (cf. Lampert et al., 2013; Vygotsky, 1978).

Our doctoral students, similar to novice teachers, experience the disconnection between (theory from) coursework and practice of teaching, hence, the "problem of enactment" (Kennedy, 1999, p. 211). It is thus an overarching strategy to facilitate enacting classroom practice, and therefore to create significantly more and deliberate opportunities to situate knowledge needed for doctoral students to understand how to implement new ideas about teaching that they learn in an academic development program (cf. Ball \& Forzani, 2009).

As peer-teachers, together with the instructors, students design a session on one of the topics related to the foundations of teaching and learning in higher education, such as how scholars develop as teachers, theoretical groundings in teaching and learning, or different teaching strategies such as leading discussions or including technology in teaching. This session design 
experience, as well as the teaching itself, are done in a collaborative and supportive environment: peer teaching is implemented to increase motivation, self-confidence and cooperation, and to decrease competitive behaviour (cf. Goldschmid \& Goldschmid, 1976). As reflection is crucial for teacher growth and development, enactment is followed by reflection on both the design experience and teaching. The aim is to enhance students' involvement in their own learning and model a way of professional inquiry into their own practice (cf. Schön, 1983, 1987).

Hence, through the peer teaching experience doctoral students analyse processes of representation and decomposition of teaching strategies by enacting discrete practices and observing their peers in these instructional situations (cf. Deshler et al., 2016). In other words, as peer teachers, doctoral students have an opportunity to co-construct and manipulate the teaching material, co-design a teaching plan together with the instructors, enact teaching collaboratively, and reflect on the teaching and planning experience. Otherwise, in their role as students, participants have a chance to observe different models and strategies of teaching.

'Designing for student learning' is another pedagogical strategy that underpins our approach to developing instructional knowledge about course design, instructional and assessment strategies, etc. In addition, it contributes to pedagogical knowledge about disciplinary and interdisciplinary perspectives to teaching and also more generic understandings that go beyond the disciplines, e.g. critical thinking or self-directed learning (cf. Shulman, 1987). Learning through the process of enactment also requires the integration of the theory of design thinking and the actual practice of planning for teaching in the discipline (including assignments, assessments etc.). In parallel with peer-teaching as a guided session design and teaching experience, doctoral students also get opportunities to apply the practices of planning or teaching within their own disciplines. In this context, it is the design thinking and instructional strategies that are the primary focus of enactment. In the CTL Certificate Program, doctoral students get introduced to the theory and the model of 'backward design' (Wiggins \& McTighe, 2005) as a guiding framework to approach the planning of university teaching. They then are encouraged on multiple occasions to practice 'backward design' thinking when working on actual teaching designs (including concrete learning goals, activities and assessments) in their own disciplines. Outputs of these design projects may take different forms: annotated session plans, full-fletched syllabi, or the format of an academic poster. These are authentic assessment tools as they require creative application of 'backward design' thinking in unique disciplinary contexts and demand students to determine pedagogical solutions, instructional and assessment strategies that are justified and appropriate for the particular contexts (Wiggins, 1998). Feedback sessions on these outputs are presented and discussed with peers and with program instructors, and encourage students to demonstrate pedagogical reasoning behind their designs and to justify their instructional solutions. Giving and receiving feedback from peers is yet another opportunity to engage in critical reflection and analysis of design processes. Enacting 'backward design' thinking through such projects further facilitates the process of professional development, since the model encourages students to shift from their own teaching to student learning, and from content coverage to an active learning approach (cf. Misic \& Rymarenko, 2019).

The third overarching principle is 'supporting the process of becoming' whereby it is meant that the development of an awareness about research behind teaching and of critical skills for reflection and self-analysis is stretched over a longer period of time, evolves gradually and should be supported within a professional community (cf. Lave \& Wenger, 1991). Hence, selfinquiry in the domain of teaching knowledge is a transformative process that proceeds with a 
conscious self-monitoring of professional growth. However, there is yet this important distinction between professional growth oriented towards external audiences (necessitated by institutional standards, assessment exercises, or credentialism) versus development meant for oneself mainly (personal and needs-driven) (Kreber, 2013, p. 75), which needs to be considered. Therefore, in our program, the carefully scaffolded creation of an online teaching portfolio constitutes the first step in consciously and systematically constructing academic professionalism (Kreber, 2013, p. 61) and a teaching persona (Parini, 2005) which may evolve long after program completion. The online teaching portfolio ultimately goes beyond its function as a collection of teaching artifacts or a program portfolio, and serves as a personal thinking lab that combines the features of an archive with those of reflective and future-oriented personal development (Dorner \& Renc-Roe, 2016). In addition to the potentials of an online platform to allow for flexibility in terms of artifact types as well as to support individual ubiquitous learning experiences, it may provide a 'home' for a sustainable online professional community which opens up prospects for shared professionalism that encompasses professional skills and competences that are learnt collectively in order to be also accepted collectively (cf. van Dellen \& van der Kamp, 2008). Finally, teaching portfolios are increasingly used as a collection of evidence of teaching and student learning and therefore often reviewed in hiring or promotional procedures as a demonstration of teaching professionalism (e.g. Little-Wienert \& Mazziotti, 2018; Seldin, Miller, \& Seldin, 2010). Hence, creating such a portfolio through the Program not only contributes to the development of CTL graduates as reflective teachers, but also provides 'visibility' as future international faculty with documented teaching experience from a rich variety of sources.

\section{CONCLUSION}

This paper focused on exploring the intellectual basis (or the framework of a program theory) of an academic development program for international doctoral students in social sciences and humanities. The program aims to cultivate a reflective scholarly approach to (disciplinary and interdisciplinary) teaching and to prepare graduates for future international teaching endeavours. Further, it encourages peer collaboration, as it sees professional communities as a source of collective learning, inspiration and innovation. We think, such professionalization of teaching practice in higher education (Lueddeke, 2003) is particularly important in geographical areas where the practice itself is lacking, programs exist sporadically or have only begun to be established. Our paper thus aimed to contribute to the literature and practice on establishing academic development programs, especially in academic environments with low institutional support for teaching and lack of formal requirements for professional development.

\section{REFERENCES}

Ball, S. J. (2003). The teacher's soul and the terrors of performativity. Journal of Education Policy, 18(2), 215-228.

Ball, D. L., \& Forzani, F. M. (2009). The work of teaching and the challenge for teacher education. Journal of Teacher Education, 60(5), 497-511. https://doi.org/10.1177/0022487109348479. 
Clegg, S. (2009). Forms of knowing and academic development practice. Studies in Higher Education, 34(4), 403-416.

Deaker, L., Stein, S. J., \& Spiller, D. (2016). You can't teach me: Exploring academic resistance to teaching development. International Journal for Academic Development, 21(4), 299-311. https://doi.org/10.1080/ 1360144X.2015.1129967.

Deshler, J., Dorner, H., \& Renc-Roe, J. (2016). Peer teaching as an opportunity for enactment and academic practice in a higher education excellence in teaching certificate program, Higher Education Conference 2016, Amsterdam, Netherlands, 2016.

Dorner, H., \& Renc-Roe, J. (2016). Doctoral students' conceptions of online teaching portfolios. An exploration of the authenticity and performativity spectrum. Zeitschrift für Hochschulentwicklung. Special Issue: Development and Socialization of Academics, 11(5), 25-43. https://doi.org/10.3217/zfhe11-05/02.

Feixas, M., \& Euler, D. (2012). Academics as teachers: New approaches to teaching and learning and implications for professional development programmes. International HETL Review, 2. https://www. hetl.org/academics-as-teachers-new-approaches-to-teaching-and-learning/.

Gibbs, G., \& Coffey, M. (2004). The impact of training of university teachers on their teaching skills, their approach to teaching and the approach to learning of their students. Active Learning in Higher Education, 5(1), 87-100. https://doi.org/10.1177/1469787404040463.

Goldschmid, B., \& Goldschmid, M. L. (1976). Peer teaching in higher education: A review. In Higher education (Vol. 5, Issue 1, pp. 9-33). Kluwer Academic Publishers. https://doi.org/10.1007/BF01677204.

Hattie, J., \& Marsh, H. (1996). The relationship between research and teaching: A meta-analysis. Review of Educational Research, 66(4), 507-542. Retrieved November 24, 2020, from http://www.jstor.org/stable/ 1170652.

Ho, A., Watkins, D., \& Kelly, M. (2001). The conceptual change approach to improving teaching and learning: An evaluation of a Hong Kong staff development programme. Higher Education, 42(2), 143169. https://doi.org/10.1023/A:1017546216800.

Jacob, W. J., Xiong, W., \& Ye, H. (2015). Professional development programmes at world-class universities. Palgrave Communications, 1(1), 1-27. https://doi.org/10.1057/palcomms.2015.2.

Jerez Yàñez, Ó., Aranda Càceres, R., Corvalán Canessa, F., González Rojas, L., \& Ramos Torres, A. (2019). A teaching accompaniment and development model: Possibilities and challenges for teaching and learning centers. International Journal for Academic Development, 24(2), 204-208. https://doi.org/10. 1080/1360144X.2019.1594238.

Kelley, B., Cruz, L., \& Fire, N. (2017). Moving toward the center: The integration of educational development in an era of historic change in higher education. To Improve the Academy, 36(1), 1-8. https:// doi.org/10.1002/tia2.20052.

Kennedy, M. M. (1999). The role of preservice teacher education. In L. Darling-Hammond, \& G. Sykes (Eds.), Teaching as the learning profession: Handbook of teaching and policy (pp. 54-86). Jossey Bass.

Kreber, C. (2013). Authenticity in and through teaching in higher education: The transformative potential of the scholarship of teaching. London and New York: Routledge.

Kreber, C., \& Cranton, P. A. (2000). Exploring the scholarship of teaching. Journal of Higher Education, 71(4), 476-495. https://doi.org/10.1080/00221546.2000.11778846.

Lampert, M., Franke, M. L., Kazemi, E., Ghousseini, H., Turrou, A. C., Beasley, H., et al. (2013). Keeping it complex: Using rehearsals to support novice teacher learning of ambitious teaching. Journal of Teacher Education, 64(3), 226-243. https://doi.org/10.1177/0022487112473837. 
Lave, J., \& Wenger, E. (1991). Situated learning: Legitimate peripheral participation. In Situated learning. Cambridge University Press. https://doi.org/10.1017/cbo9780511815355.

Little-Wienert, K., \& Mazziotti, M. (2018). Twelve tips for creating an academic teaching portfolio. Medical Teacher, 40(1), 26-30.

Lueddeke, G. R. (2003). Professionalising teaching practice in higher education: A study of disciplinary variation and "teaching-scholarship". Studies in Higher Education, 28(2), 213-228. https://doi.org/10. 1080/0307507032000058082.

Mezirow, J. (1991). Transformative dimensions of adult learning. Jossey-Bass.

Misic, G., \& Rymarenko, M. (2019). Supporting doctoral candidates as early career teachers: Addressing teaching challenges through design. Third EuroSoTL conference: Exploring new fields through the scholarship of teaching and learning, 964-967.

Nyquist, J. D., \& Sprague, J. (1998). Thinking developmentally about TAs. In M. Marincovich, J. Prostko, \& F. Stout (Eds.), The professional development of graduate teaching assistants (pp. 61-88). Anker Publishing Company.

Parini, J. (2005). The art of teaching. New York: Oxford University Press.

Pylväs, L., \& Nokelainen, P. (2021). Academics' perceptions of intercultural competence and professional development after international mobility. International Journal of Intercultural Relations, 80, 336-348. https://doi.org/10.1016/j.ijintrel.2020.10.004.

Quinn, L. (2012). Understanding resistance: An analysis of discourses in academic staff development. Studies in Higher Education, 37(1), 69-83. https://doi.org/10.1080/03075079.2010.497837.

Ramsden, P. (1994). Describing and explaining research productivity. Higher Education, 28(2), 207-226. Retrieved November 24, 2020, from http://www.jstor.org/stable/3447753.

Rogers, P. J., Petrosino, A., Huebner, T. A., \& Hacsi, T. A. (2000). Program theory evaluation: Practice, promise, and problems. New Directions for Evaluation, 2000, 5-13. https://doi.org/10.1002/ev.1177.

Schön, D. A. (1983). The reflective practitioner: How professionals think in action. New York: Basic Books, Inc.

Schön, D. A. (1987). Educating the reflective practitioner: Toward a new design for teaching and learning in the professions. Jossey-Bass.

Seldin, P., Miller, J. E., \& Seldin, C. A. (2010). The teaching portfolio: A practical guide to improved performance and promotion/tenure decisions. John Wiley \& Sons.

Shulman, L. (1987). Knowledge and teaching: Foundations of the new reform. Harvard Educational Review, 57(1), 1-23. https://doi.org/10.17763/haer.57.1.j463w79r56455411.

van Dellen, T., \& van der Kamp, M. (2008). Work domains and competencies of the European adult and continuing educator. In E. Nuissl, \& S. Lattke (Eds.), Qualifying adult learning professionals in Europe (pp. 63-74). W. Bertelsmann.

Vygotsky, L. S. (1978). Mind in society: The development of higher psychological processes. Harvard University Press.

Wiggins, G. (1998). Ensuring authentic performance. In Educative assessment: Designing assessments to inform and improve student performance (pp. 21-42). San Francisco: Jossey-Bass.

Wiggins, G., Wiggins, G. P., \& McTighe, J. (2005). Understanding by design. Ascd.

Open Access. This is an open-access article distributed under the terms of the Creative Commons Attribution-NonCommercial 4.0 International License (https://creativecommons.org/licenses/by-nc/4.0/), which permits unrestricted use, distribution, and reproduction in any medium for non-commercial purposes, provided the original author and source are credited, a link to the CC License is provided, and changes - if any - are indicated. 